\title{
Design and Implementation of Service and Management System of Agricultural Technicians
}

\author{
Yang $\mathrm{Lu}^{1,2}$, Furong Wang ${ }^{1,2^{*}}$, Changshou Luo ${ }^{1,2}$, Weishui $\mathrm{Yu}^{1,2}$, Jun $\mathrm{Yu}^{1,2}$ \\ ${ }^{1}$ Institute of Agricultural Information and Economics,Beijing Academy of Agriculture and Forestry Sciences, No.9, Shuguang \\ Huayuan Road,Beijing,China \\ ${ }^{2}$ Rural Distance Information Service Engineering Technology Research Center of Beijing, No.9, Shuguang Huayuan \\ Road,Beijing,China
}

\begin{abstract}
This paper proposes a design idea of service and management system of agricultural technicians, which includes the design of management system, logical structure, service flow and management module. It introduced "DiDi Agrotechnique" product which developed based on this design idea. The "DiDi Agrotechnique" product includes two parts: One is mobile phone APP which realized one-button Q\&A operation on agricultural technical consultation, the other is back-end management system, which realized management of agricultural service process and automatic statistics of service data. This product has great significance for integrating agricultural technicians, providing $\mathrm{O} 2 \mathrm{O}$ agricultural technical services, and improving management efficiency, which has the practical value for extensive use.
\end{abstract}

\section{Introduction}

At present, with the rapid development of computer science and network technology, the PC and mobile devices have been applied widely, which creates conditions for the establishment and application of a unified management system. The agricultural technology need an integrated management system to grasp the dynamics of agricultural technology promotion in time, accelerate the innovation of the agricultural technology and achieve systematic and standardized agricultural technology promotion. In recent years, government departments, scientific research institutions, and enterprises have successively established the network system of agricultural technology, which facilitated the solution of technical problems encountered by farmers in the agricultural production process and meanwhile integrated the relevant agricultural technical resources.

However, through field investigation, it has been found several problems, such as the cost of agricultural expert services is high, experts general are far away from farmers and cannot quickly reach the scene to solve the problem. Then we also found that the operation of agricultural technology consulting services product in the market is complicated and the implementation scope is not widely. The basic-level agricultural technicians have the characteristics of being familiar with their local agricultural environment and technology needs, and sloving problems quickly, they can provide convenient

\footnotetext{
* Corresponding author: Furong Wang wfr828@126.com
}

door-to-door service. However, the rate of integration and utilization of the agricultural technician resources is not high, and the superior departments are unable to grasp their specific service conditions during the management process. So corresponding service products and management systems should be designed to integrate and manage agricultural technology resources, which will achieve $\mathrm{O} 2 \mathrm{O}$ services of agricultural technology and monitor the whole service process. These products and systems are beneficial to quantify and assess the service of agricultural technique, and promote the service quality of basic-level agricultural technicians.

\section{System design}

\subsection{Integrated design idea}

\subsubsection{Management System design}

Combined with the agricultural administrative management system, and the specific requirements of managers and users, the management system involves four layers as shown in Figure 1. The provincial (municipal) level administrators have the authority to audit and check the data which submitted by the subordinate districts and counties, they can also manage the background system. The county (district) level 
administrator has the authority of account checking, account allocation and background system management. Basic-level agricultural technicians are the ties that connect farmers and superior management departments, in order to promote the management and the service, they are necessary to $\log$ in with a superior account number and fill in real-name information. Farmers are users of this system, need to register and fill the basic information before they use it.

\begin{tabular}{|c|c|c|c|}
\hline Provincial(Municipal) & County (District) & Agricultural__ & Farmer \\
\hline Level Administrator & Level Administrator & Technician & \\
\hline
\end{tabular}

Figure.1. Management system design.

\subsubsection{Logical structure design and developme-nt technology}

According to the logical layering principle and object oriented principle, the whole system can be divided into three layers: the client layer, the application layer, and the data layer. The client layer is designed based on the PC and the mobile device, its specific form can be webpage or APP. Operator can use defined services or functions to realize human-computer interaction. The client layer displays the system output data; The application layer analyzes and processes the customer's application request, calculates the data and then returns to the client layer; The data layer is a database management system, the main function is data storage and management.

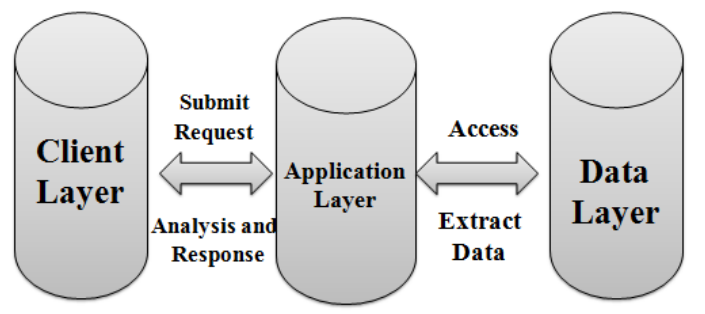

Figure.2. System logic structure diagram.

The front-end service software and back-end management platform of the system can be written in C\# and JAVA languages, developed and designed with Visual Studio, SQL Sever, SQLite, Webservice, and GIS components.

\subsection{Service flow design}

To get through the channels of farmers, agricultural technicians and experts, and establish Q\&A database, the service system design is divided into two parts. When user asks a question with device, the question will be sent in the form of voice, text, pictures, etc. On one hand, if the agricultural technician can solve it, they will provide telephone or on-site service. But if the agricultural technician cannot answer it, the system will sent the question to the back-end expert, who contact the user to resolve it through remote device. Finally, the user evaluate the service and the entire process ended. On the other hand, in order to realize online self-service inquiry, the system will establish Q\&A database and background manager will record and classify the user's questions. The questions of voice can be converted into text by using TTS, then using natural language processing technology to achieve precise intelligent Q\&A service (Specific process shown in Figure 3).

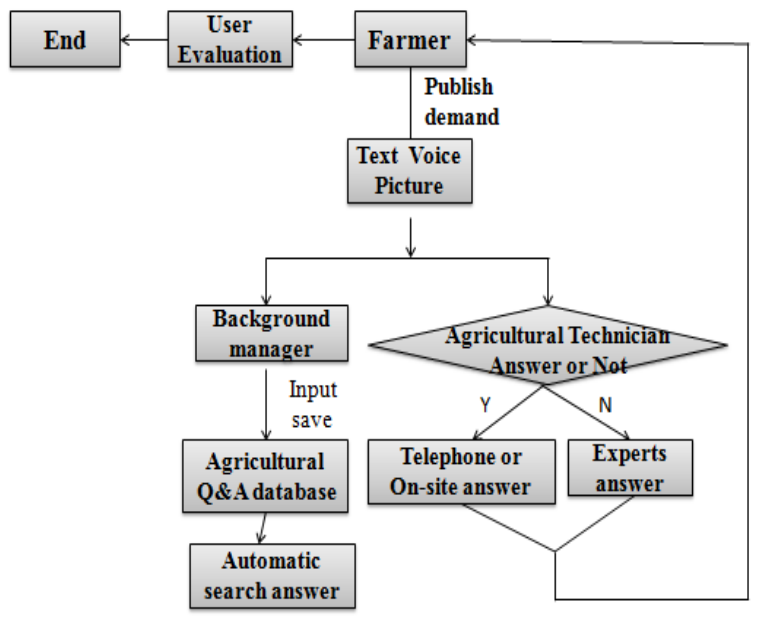

Figure.3. The diagram of service flow.

\subsection{Management module design}

The agricultural technology management system platform mainly includes five modules: (1) Personnel information management module, managers can use this module to manage and audit the information of farmers, agricultural technicians and experts; (2) Announcement management module, the system regularly push policy and technical news, system notifications. (3) Question database management module, through this module, background manager can check, edit and answer the questions which collected by the front-end device. (4) Statistical analysis module, managers can check the status of registration, demand, and service at any time. This module provides the function of automatic statistics and analysis of data, then it can form and export chart. (5) Dictionary management module, this module can be used to construct fields of proprietary information, such as domain classification, demand classification, administrative classification, etc.

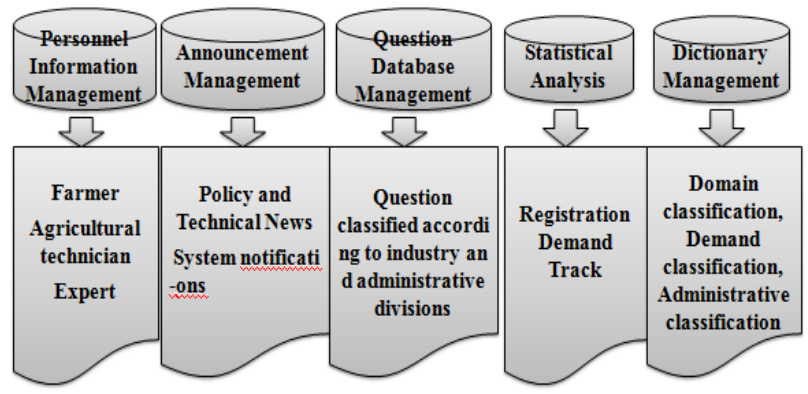

Figure.4. The diagram of agricultural technology management system platform.

\section{System implementation and application}


By combining the design concept of agricultural technician service and management system, using "3S" Technologies, Webservice technology, storage and management technology, we develope "DiDi Agrotechnique" APP and back-end management system. The product can provide users with convenient and "O2O" agricultural technology services, it could integrate basic-level agricultural technology resources, and connect farmers and agricultural experts of college and research institutes. In addition, the system can provide a management platform for the superior management department to timely acquire and analyze the data such as the service of agricultural technicians and the needs of farmers.

\subsection{Implementation of "DiDi Agrotech-nique" APP}

In order to make the user easy to use, the product adopts one-button Q\&A service form, UI interface uses visual map positioning technology. Farmers can register and use the APP after filling in a few simple information. Click the "Demand" button below to enter the "Publication Requirements" page. Farmers can make an appointment to solve, and then simply describe the questions they need to consult in the form of voice or text, and upload live photos. After the agricultural technician answers the question, the farmer can evaluate the service of the agricultural technician and give marks to the agricultural technician. If the question is not answered, the system will transfer the question to the back-end expert of the 12396 Agricultural Technology Service Hotline to solve it.

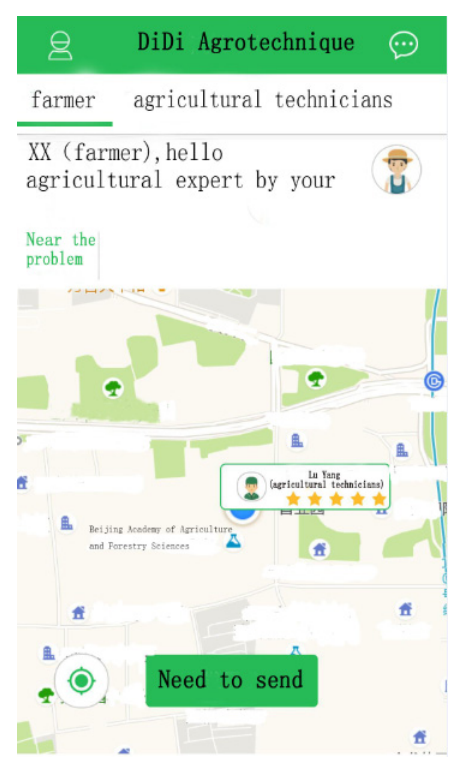

Figure.5. "DiDi Agrotechnique"APP page.

The agricultural technician operates with the grab task mode. When a farmer sends out a demand, the agricultural technician will receive a system notification ( As shown in Figure6).The agricultural technician can judge whether to grab the task by checking the details of the demand. After accepting the task successfully, it can be solved by calling or going to the scene. If the agricultural technician chooses to go to the site, the system will enter the map interface to navigate, and the service track will be also recorded by the backend system. If the agricultural technician who has grabbed the task can not solve this problem, he can cancel the order or query the answer by consulting the expert and then answer it. After the task is completed, the agricultural technician needs to record and submit the solution.

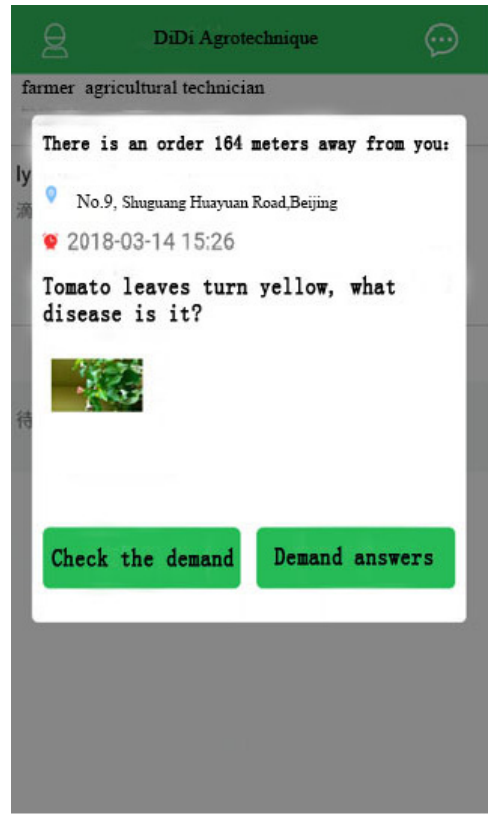

Figure .6.Interface of agricultural technician receive notification.

\subsection{Implementation of "DiDi Agrotech-nique" Back-end Management Syst-em}

The "DiDi Agrotechnique" Back-end Management System is the platform for superior agricultural department to manage basic-level agricultural technicians .It has the characteristics of

clear hierarchy, comprehensive and automatic statistics. The system is divided into 8 modules: Demand Management, User Management, Subsidy Management, Statistical Analysis, 12396, System Notification, Question Feedback, and Dictionary Management. Each module is set up submodules, administrators can easily access, manage, and analyze data through them.

First, the administrator log in the account, by the Demand Management module, he can check requirement list according to the key word, service method, order time, and other categories, and then he can also check the service track of the agricultural technician, as shown in Figure8.In the User Management module, administrator can manage the information of the agricultural technicians and farmers, and audit the account of the agricultural technicians. At the same time, the geographical distribution of the users and the check-in status can be viewed. Subsidy Management detailed record on the examines and rewards of the agricultural technicians, and it can export the corresponding data sheet. Statistical Analysis module realizes automatic data analysis result. The user registration status, demand status, service status, etc. are displayed by means of charts which is shown in the right interface of Figure 7. 12396 module realizes the 
connection of "DiDi Agrotechnique" Back-end Management System and 12396 Agricultural Technology Service Hotline. It links 12396 expert resources and agriculture Q\&A database together. 8.System Notification module manages system messages display of APP. 9.Question Feedback module can real-time control the user's reaction during use. 10.Dictionary management module includes management of domain list and requirement type list, administrators can set service time of agricultural technicians in this module.

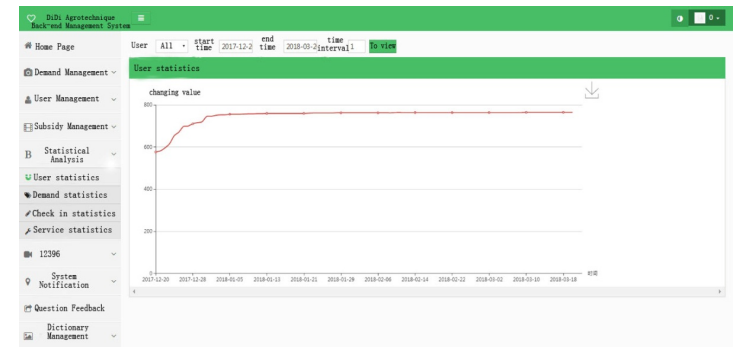

Figure.7.Interface of "DiDi Agrotechnique" Back-end Management System.

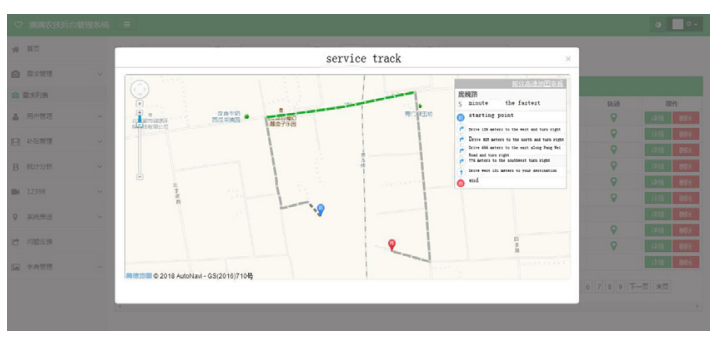

Figure .8.Service track of the agricultural technician.

\section{Conclusion}

Agricultural technicians are an important part of the agricultural technology promotion and service system. The Service and Management System of Agricultural technicians designed in this paper can make basic-level agricultural technology resources efficiently used and promote the optimum allocation of agricultural technician. At the same time, this system can provide an efficient information platform for agricultural technician services, provide convenient $\mathrm{O} 2 \mathrm{O}$ services for farmers, and provide accurate management and decision-making data support for government management departments.

"DiDi Agrotechnique"APP is developed based on above system design concept, it is a mobile phone product for service and management of agricultural technology promotion. The product reformed agricultural technology services means and functional design of system, established a bridge of agricultural technicians and farmers through mobile. It can improve the precision of agricultural technology promotion work, provide more convenient and efficient $\mathrm{O} 2 \mathrm{O}$ agricultural technology services for famers, and broaden the service scope and service methods of the basic-level agricultural technicians. "DiDi Agrotechnique" Back-end Management System can record and track the service information of each agricultural technician in detail, and realize the detailed assessment of individual performance and work ability of agricultural technicians. At present, the product has been applied in demonstration areas, which has obtained great effects. After continuous improving and upgrading, it will have the practical value for extensive use.

\section{ACKNOWLEDGEMENTS}

The research work was supported by the Beijing excellent talent project: Research on key technology of $m$ anmachine conversation in agricultural science and techn ology consultation and application of Be-

ijing, Tianjin and Hebei, the international cooperation fun d of BAAFS: A comparative study on the agricultural sci ence and technology information servicee system in China, the United States and Canada, the $\backslash 2018$ Beijing financing agricultural funds: Application and demonstration of "Nongkexiaozhi" conslting service robot and WebAPP in agricultural productio $\mathrm{n}$, the young scientist fund of BAAFS: Analysis of omnipotent agricultural technicians' training effect and relevant affecting factors in Beijing (NO.QNJJ201803)

\section{REFERENCES}

1. CHEN Xin-zhong, LI Fang-fang. Retrospect and Prospect of Research on Our Agricultural Technology Extension [J]. Journal of Huazhong Agricultural University(Social Sciences Edition, 2014, 33(5):24-33.

2. Junhui Shao. The Design and Implementation of Primary Agricultural Technology Extension System for Bazhou[D]. Shandong University, 2015.

3. 3 .MENG Meng. Model Design of Closed-loop Supply Chain for Tropical Agricultural Products in Hainan Province $[\mathrm{J}]$. Chinese Journal of Tropical Agriculture, 2016, 36(10):87-92.

4. Yu W, Luo C, Zheng Y, et al. Research on the development and preliminary application of Beijing agricultural sci-tech service hotline WebApp in agricultural consulting services[J]. 2017, 231(1):012030.

5. Wei Chen, Shupu Guo. Studies on Progress and Trend of Agricultural and Rural Informatization in China, [J]. Hubei Agricultural Sciences, 2013,52(22) 5625-5629 